\title{
Inclusão e Cidadania Digital no Brasil: a (des) articulação das políticas públicas
}

\section{Digital Inclusion and Citizenship in Brazil: the (dis) articulation of public policies}

\author{
Angela Maria Grossi de Carvalho, Marcos Tuca Américo
}

\begin{abstract}
The incipient but quickly expansion action on the Information and Communications Technologies (ICT) in Africa it is now just having different impact on these societies. One of these relates bear on how users are identified with these tools. Just like that we find individuals identify as bloggers, twitter followers or cyber activist.
\end{abstract}

This contribution analyzes the Senegal's fact where a successful use of social nets and web 2.0 tools experience (at least in repercussion) as social and political involvement while presidential elections in 2012 is tied to come back an identity: Cyber activist. Senegalese circumstance shows us how this identity has a personal and assertiveness dimension as well collective aspects of belonging to a community. One as much as the other, show us personal traits in contrast to previous beliefs, basically because it fuse and confuse virtual and reality.

Due to dynamics from expanding technology, this identity is youthful and urban, but not only. This situation creates new dynamics at least in this affected group. For this reason, besides knowing emergence and evolution of this fact, it raises some of the involvement in social and political involvement from groups traditionally "invisible". Beyond the new social behavior there are new changes in the rules of the game in order to start new social revolution.

KEYWORDS: ITC, social network, participation, society, identity. 


\section{Resumo}

A mudança da sociedade industrial para a pós-industrial significou uma mudança substancial na importância com novas formas de processamento informacional, novas estruturas e tecnologias. A chamada sociedade da informação vai criando novas possibilidades para os setores econômico, político, cultural e social. No entanto, se percebe novas fronteiras sendo erguidas ao privar a população, em seu todo, de ter acesso e condições de uso das tecnologias da informação e comunicação (TIC) e de toda a estrutura oferecida pelas redes digitais. Refletir sobre essas mudanças e o papel do estado na gestão de políticas públicas que tenham por finalidade a diminuição da brecha digital é o objetivo desse artigo. Por meio de uma metodologia que se utiliza das pesquisas bibliográficas e documental, buscamos demonstrar que as ações governamentais ainda são espaças e insuficientes.

Palavras-chave: Sociedade da Informação. Inclusão Digital. Cidadania Digital. Política Pública Social. Informação e Tecnologia.

\section{Introdução}

Muitas são as nomenclaturas dadas à sociedade da informação, sua construção remonta às rápidas e exponenciais constituições das estruturas de informação dos séculos passados, em especial o século XX, com forte incidência a partir da Revolução Industrial, que abre caminho para o nascimento da sociedade da informação, devido a sua dependência da tecnologia e da ciência. De acordo com Mattelart (2002, p. 08)

\footnotetext{
Essa noção de sociedade da informação se formaliza na sequência das máquinas inteligentes criadas ao longo da Segunda Guerra Mundial. Ela entra nas referências acadêmicas, politicas e econômicas a partir do final dos anos 1960. Durante a década seguinte, a fábrica que produz o imaginário em torno da nova "era da informação" já funciona a pleno vapor. Os neologismos lançados na época para designar a nova sociedade só mostrarão seu verdadeiro sentido geopolítico às vésperas do terceiro milênio com o que se convencionou chamar de "revolução da informação" e com a emergência da Internet como nova rede de acesso público.
}

A partir dessa alteração, começam a surgir novas formas de denominar a sociedade, assim "as expressões sociedade industrial, pré-industrial e pós-industrial são sequências conceituais ao longo do eixo da produção e dos tipos de conhecimento utilizados" (BELL, 1973, p. 25).

0 aparecimento da expressão "sociedade da informação" começa quando a expressão "pós-industrial" passa a ser rejeitada por Zbignieuw Brzezinski por ser vazia de conteúdo; 
ele então propõe a substituição por "sociedade tecnotrônica". Para Brzezinski (1971, p. 11), "a nova tecnologia das comunicações eletrônicas é que havia inaugurado a nova era". A expressão "sociedade tecnotrônica" não vingou, embora sua ideia tivesse fundamento para tal. Bell (1973, p. 467) dizia que "a sociedade pós-industrial é uma sociedade da informação, como a sociedade industrial é uma sociedade produtora de bens". Para Freitas (2002, p. 03), o termo teve o "primeiro uso nos EUA [...] feito pela American Society for Information Science (ASIS), que realizou reunião anual com o tema The Information Conscious Society, em 1970".

De acordo com os autores que veem a tecnologia como a espiral da sociedade da informação, os sinais de mudança são percebidos por meio do desenvolvimento e ampliação do uso de tecnologias de processamento, estocagem e transmissão da informação, com grande evidência no ato de processar informações em variadas atividades da sociedade sendo permeadas pela convergência de tecnologias de telecomunicação (FREITAS, 2002). Para Masuda (1968, p. 42)

\begin{abstract}
a base dessa sociedade será a produção de valores informacionais, intangiveis, em substituição aos valores tangíveis, em que prevalece a indústria do conhecimento, quaternária, expandindo-se a partir de uma economia sinérgica e da utilização compartilhada dos bens. A sociedade da informação será [...] uma comunidade voluntária, voltada para o benefício social.
\end{abstract}

Assim, conhecimento e informação se tornaram recursos estratégicos e "os agentes transformadores da sociedade pós-industrial [...] da mesma maneira que a combinação de energias, recursos e tecnologias mecânicas foram os instrumentos transformadores da sociedade industrial" (BELL, 1980, p. 531). De acordo com Kurmar (1997, p. 21), "a ideia básica da sociedade pós-industrial, porém, era a evolução para uma sociedade de serviços e o rápido crescimento de oportunidades de emprego para profissionais liberais e de nível técnico".

Bell (1980, p. 27-28), propõe que o significado da sociedade da informação seja observado em cinco dimensões, sejam elas:

1. Setor econômico: a mudança de uma economia de produção de bens para uma de serviços;

2. Distribuição ocupacional: a preeminência de classe profissional e técnica;

3. Princípio axial: a centralidade do conhecimento teórico como fonte de inovação e de formulação política para a sociedade;

4. Orientação futura: o controle da tecnologia e a distribuição tecnológica; 
5. Tomada de decisões: a criação de uma nova "tecnologia intelectual".

Podemos, portanto, entender por "sociedade da informação" a sociedade que está em constituição, na qual a utilização das tecnologias de armazenamento e transmissão de dados e informação está presente em vários setores e processos, com interferência direta na economia, no modo de produção, na reorganização e sistematização das formas de conhecimento.

Com a introdução das tecnologias, acredita-se em um novo "paradigma tecnoeconômico", um "fenômeno global" capaz de transformar as atividades sociais e econômicas. Da mesma forma, a ausência de conhecimento sobre essas tecnologias, por parte das nações, pode gerar um atraso mundial da sociedade global. 0 uso da informação deve estar atrelado à melhoria da qualidade educacional e ao incremento da alfabetização da população. Mas o que se observa atualmente é que a simples conectividade, ou simples acesso às TIC, não garante ao cidadão o uso da informação, como se ela por si pudesse fazer com o que o indivíduo conectado possa encontrar os caminhos, processar, disseminar e transformar a informação recebida e a ser transmitida.

0 encurtamento das distâncias via rede proporciona uma aproximação entre as nações, além de múltiplas possibilidades informacionais para os mais diferentes grupos sociais. Chegaríamos ao mundo fantástico das interconexões e da quebra de barreira, já que "a melhor maneira de manter e desenvolver uma coletividade não é mais erguer, manter ou estender fronteiras, mas alimentar a quantidade e melhorar a qualidade das relações em seu próprio interior [...]" (LÉVY, 2001, p. 28 grifo do autor).

A Internet é um dos poucos meios de informação e comunicação que consegue tornar informação e conhecimento acessiveis a qualquer pessoa, desde que esteja conectada à rede e que tenha um grau mínimo de alfabetização para que seja possível compreender os conteúdos disponíveis, que quando acessíveis, não necessitam de intermediários e podem ser processados com facilidade. Isso faz dela um meio necessário para que os povos possam se desenvolver cultural e economicamente dentro da lógica da sociedade da informação, lembrando sempre que não significa que a tecnologia por si só poderá resolver as questões de disparidades sociais, culturais e econômicas, mas pode auxiliar numa compreensão e uso diferenciado dos sistemas de informação.

Diante desse cenário, discutimos as questões relacionadas à inclusão e cidadania digital no Brasil, por meio da abordagem das políticas públicas gestadas pelo Estado na intenção de se inserir o Brasil na Sociedade da Informação. Como metodologia utilizamos a pesquisa exploratória, com os procedimentos de pesquisa bibliográfica e documental, com o objetivo de apontar como as ações vem sendo articulas e gestadas pelo Estado. 


\title{
Inclusão Digital
}

Eu não sei fazê internet, video-cassete, os carro loco,

Atrasado eu tô um pouco sim,

Tô, eu acho... [sic]

Trecho da música "Negro Drama" - Racionais MC's (2002) ${ }^{1}$

\begin{abstract}
A letra da música da banda de rap "Racionais MC's"2 descreve o sentimento daqueles que foram excluidos diante do processo de globalização que transformou, além dos meios e formas de produção, a comunicação e a economia criativa, responsáveis pela produção do capital simbólico tão presente na chamada "Economia da Atenção" (GOLDHABER, 1997) decorrente da comunicação ubíqua proporcionada pela internet (MAGNONI; AFINNI; AMÉRICO, 2007). Conforme Leiner et al. (2011), nunca na história da humanidade uma criação tecnológica afetou em tão pouco tempo um número tão significativo de pessoas como ocorreu com a rede mundial de computadores. De acordo com o "Relatório sobre análise em provedores de banda larga" do Instituto Nacional de Metrologia, Normalização e Qualidade Industrial (INMETRO, 2011)
\end{abstract}

\begin{abstract}
A Internet é um privilégio da contemporaneidade, representando hoje o maior repositório de informações acessiveis a qualquer pessoa que a acesse de qualquer parte do mundo. [...] 0 que a tornou tão diferente das outras invenções humanas foi o insignificante periodo de tempo em que ela precisou para ser usada por milhões de pessoas. A eletricidade (1873), por exemplo, atingiu 50 milhões de usuários depois de 46 anos de existência. 0 telefone (1876) levou 35 anos para atingir esta mesma marca. 0 automóvel (1886), 55 anos. 0 rádio (1906), 22 anos. A televisão (1926), 26 anos. 0 microcomputador (1975), 16 anos. 0 celular (1983), 13 anos. A Internet (1995), por sua vez, levou apenas 4 anos para atingir 50 milhões de usuários no mundo.
\end{abstract}

0 mesmo relatório supracitado afirma que a exclusão digital é uma grande barreira para o desenvolvimento pleno do país, principalmente nos estados das regiões norte e nordeste. O Plano Nacional de Banda Larga - PNBL - (também chamado de "Brasil Conectado") em execução pelo Ministério das Comunicações afirma que " [...] o acesso em banda larga é caracterizado pela disponibilização de infraestrutura de telecomunicações que possibilite tráfego de informações contínuo, ininterrupto e com capacidade suficiente para as aplicações de dados, voz e vídeo mais comuns ou socialmente relevantes." (BRASIL, 2010, p.18). Feliciano (2008, p.15) reafirma a idéia discutida por Waiselfisz (2007) em seu texto Mapa das Desigualdades

1 Música gravada no CD "Nada como um dia após o outro" (2002). Letra disponível em: <http://www.vagalume.com. $\mathrm{br} /$ racionais-mcs/negro-drama.html>. Acesso em: 23 jun. 2011.

2 Informações sobre a banda disponiveis em: <http://pt.wikipedia.org/wiki/Racionais_MC's>. Acesso em: 24 jun. 2011. 
Digitais no Brasil que a sociedade globalizada tem como atributo a "[...] relação muito próxima entre as atividades humanas e as tecnologias digitais, onde os marginalizados encontram-se na periferia do conhecimento [...]", idéia que confronta com o pensamento do geógrafo Milton Santos $^{3}$ que afirma que estas mesmas tecnologias é que darão voz aos excluídos. Conforme o IPEA (2010, p.03) em seu comunicado Análise e recomendações para as políticas públicas de massificação de acesso à internet em banda larga:

- As infraestruturas de acesso à internet são os canais por onde é transportado o principal ativo do século XXI: o conhecimento.

- No Brasil esse acesso é bastante desigual em termos sociais e regionais, gerando mais uma fonte de desigualdade em nossa sociedade.

- Esse fenômeno é amplificado pela constatação de que, segundo consenso formado entre especialistas da área, a convergência tecnológica e a integração entre diferentes serviços colocam a internet como a principal plataforma de comunicação do futuro, sucessora natural das redes de telefonia e radiodifusão.

Fica patente desta forma que "[...] agregar valor aos não-incluídos significa implementar ações que disponham recursos tecnológicos e processos educacionais integrados às demais atividades de políticas públicas." (FELICIANO, 2008, p.16). A partir do Quadro 1 é possivel estabelecer comparações entre as políticas e metas para a inserção digital entre diversos países e o Brasil.

Quadro 1. Políticas e metas para a inserção digital entre diversos países e o Brasil.

\begin{tabular}{|c|c|c|}
\hline País & $\begin{array}{l}\text { Horizonte } \\
\text { de Tempo }\end{array}$ & Principal meta \\
\hline Alemanha & $2009 \cdot 2018$ & $\begin{array}{l}\text { Levar banda larga de até } 1 \mathrm{Mbps} \text { a } 100 \% \text { dos domicilios até } 2010 \text {. Acesso a } 50 \mathrm{Mbps} \\
\qquad \text { para } 75 \% \text { dos domicílios até } 2014 .\end{array}$ \\
\hline $\begin{array}{l}\text { Austrália } \\
\text { Sề } \because\end{array}$ & $2010-2017$ & $\begin{array}{l}\text { Levar banda larga de } 100 \text { Mbps por fibra ótica a } 90 \% \text { dos domicílios, escolas e } \\
\text { empresas. Acesso via rádio para os outros } 10 \% \text {. }\end{array}$ \\
\hline & $2011-2014$ & $\begin{array}{l}\text { Levar banda larga com velocidade de } 512 \mathrm{Kbps} \text { a preços populares aos } 1.163 \\
\text { municípios brasileiros. }\end{array}$ \\
\hline Can & $2009-2013$ & Levar cobertura banda larga a todas as comunidades do país. \\
\hline Cingapura & $2009 \cdot 2012$ & $\begin{array}{l}\text { Conectar domicílios e empresas à banda largaultra-rápida em fibra ótica. Atingir } \\
\text { uma meta de } 60 \% \text { de penetração de banda larga domiciliar em } 2010 \text {. }\end{array}$ \\
\hline Coréia do Sul & $2009 \cdot 2013$ & $\begin{array}{l}\text { Acessos banda larga de } 1 \text { Gbps até 2013. Rede de banda larga móvel capaz de } \\
\text { suportar } 40 \text { milhões de assinantes. }\end{array}$ \\
\hline
\end{tabular}

3 Conforme idéias apresentadas no documentário "Encontro com Milton Santos: 0 mundo global visto do lado de cá" de Silvio Tendler (2006). 


\begin{tabular}{|c|c|c|}
\hline \multicolumn{1}{|c|}{ Espanha } & $2009-2012$ & Levar banda larga a toda área rural, com investimento em fibras óticas na rede de \\
transporte.
\end{tabular}

Fonte: Relatório sobre análise em provedores de banda larga (INMETRO, 2011).

Para incluir digitalmente é necessário entender que a exclusão de camadas de cidadãos em determinadas atividades humanas é fruto da luta pelo poder e da divisão social do trabalho presentes na história da humanidade que resulta na ausência de equidade social, política e econômica. Feliciano (2008, p.63-65), faz um estudo exploratório sobre as definições e conceitos relacionados à inclusão digital que são descritas no Quadro 2.

Quadro 2. Síntese do estudo exploratório sobre as definições e conceitos relacionados à inclusão digital.

\begin{tabular}{|l|l|}
\hline Autor & Definição/Conceito \\
\hline SILVEIRA (2001) & $\begin{array}{l}\text { Universalização do acesso ao computador conectado à Intemet, bem } \\
\text { como ao domínio da linguagem básica para manuseá-lo com } \\
\text { autonomia. }\end{array}$ \\
\hline SCHWARTZ(2005) & $\begin{array}{l}\text { A definição de inclusão digital ainda é assunto polêmico. Para esse } \\
\text { autor, a tecnologia da telefonia móvel é digital, portanto, seu } \\
\text { conteúdo também o é. Dessa forma, quem usa celular está incluido } \\
\text { digitalmente? Falar em inclusão digital como a propriedade de um } \\
\text { computador, navegando pela Internet é muito restritivo. Está } \\
\text { surgindo uma nova malha ou rede de serviços e conteú dos que vai } \\
\text { muito além do computador. }\end{array}$ \\
\hline $\begin{array}{l}\text { DIGITAL DIVIDE } \\
\text { NETWORK-UIT } \\
\text { (2005) }\end{array}$ & $\begin{array}{l}\text { Refere à brecha existente entre aqueles que conseguem efetivamente } \\
\text { acessar as tecnologias da informação e da comunicação, tais como a } \\
\text { Intemet, e aqueles que não conseguem. }\end{array}$ \\
\hline $\begin{array}{l}\text { RANGEL (apud } \\
\text { GASPARETTO,2006) }\end{array}$ & $\begin{array}{l}\text { Processo em que uma pessoa ou um grupo passa a participar dos } \\
\text { métodos de processamento, transferência e armazenamento de } \\
\text { informações que já são do uso e do costume de um ou outro grupo, } \\
\text { passando a ter os mesmos direitos e os mesmos deveres dos já } \\
\text { participantes do grupo já incluído. }\end{array}$ \\
\hline
\end{tabular}




\begin{tabular}{|l|l|}
\hline $\begin{array}{l}\text { BAGGIO (apud } \\
\text { GASPARETTO, 2006) }\end{array}$ & $\begin{array}{l}\text { O analfabetismo digital, ao afetar a capacidade de aprendizado, a } \\
\text { conectividade e a disseminação de informações, gera consequeên cias } \\
\text { virtualmente em todos os campos da vida do individuo. A } \\
\text { transformação de informação em conhecimento pelo usuário } \\
\text { permitirá configurar um verdadeiro mapa de oportunidades politicas } \\
\text { de informação digital. }\end{array}$ \\
\hline BALBONI(2007) & $\begin{array}{l}\text { O excluído digital é o indivíduo que não dispõe de recursos materiais } \\
\text { e também de conhecimentos para promover o acesso, interagir, } \\
\text { apropriar-se e produzir conteúdos por meio da rede. }\end{array}$ \\
\hline $\begin{array}{l}\text { INSTITUTO DE } \\
\text { TECNOLOGIA } \\
\text { SOCIAL-INTE (2007) }\end{array}$ & $\begin{array}{l}\text { A tecnologia social compreende o conjunto de técnicas e } \\
\text { metodologias transformadoras, desenvolvidas e/ou aplicadas na } \\
\text { interação com a população e apropriadas por ela, que representam } \\
\text { soluções para inclusão social e melhoria das condições de vida, dos } \\
\text { que não possuem condições de acesso. }\end{array}$ \\
\hline $\begin{array}{l}\text { REDE DE } \\
\text { TECNOLOGIA } \\
\text { SOCIAL (2008) }\end{array}$ & $\begin{array}{l}\text { A tecnologia social compreende produtos, técnicas e/ou } \\
\text { metodologias reaplicáveis, desenvolvidos na interação com a } \\
\text { comunidade e que representem efetivas soluções de transforma ção } \\
\text { social, sobretudo para a parcela da população que vive à margem } \\
\text { dessas ações. }\end{array}$ \\
\hline WIKIPEDIA (2008) & $\begin{array}{l}\text { Projetos e ações que facilitam a interação de pessoas de baixa renda com } \\
\text { as tecnologias da informação e comunicação (TICs). Dessa forma, } \\
\text { proporciona-se acesso a informações disponiveis na rede mundial de } \\
\text { computadores para estes usuários, além de possibilitar a produção local } \\
\text { de conteúdos na rede. Proggamas de inclusão digital se transformam em } \\
\text { grandes desafios para os govemos de países subdesenvolvidos e em }\end{array}$ \\
\hline
\end{tabular}

Fonte: Feliciano (2008, p.63-65).

Destarte, é preciso compreender a inclusão digital como uma atividade "[...] inserida em contextos sociais que estimulem e permitam não somente o processo de incluir digitalmente, mas de formação individual e coletiva de cidadãos, democratizando a informação e como meio de produção do conhecimento [...]" (FELICIANO, 2008, p.60) o que configura um novo cenário onde as questões referentes aos usos das tecnologias e o fluxo da informação são novas questões políticas e sociais decorrentes da globalização (SILVEIRA, 2001).

\section{Cidadania Digital}

0 compartilhamento e o acesso às informações passaram por várias fases, desde a distribuição irrestrita até o processamento e organização mais sistemáticos dos conteúdos da rede. Muitas outras fases se anunciam com a passagem da chamada Web $2.0^{4}$ para a Web

4 "Web 2.0 representa a transição para um novo paradigma onde a colaboração ganha força suficiente para concorrer com os meios tradicionais de geração de conteúdo" (PATRIOTA; PIMENTA, 2008, p. 2). 
Semântica, ou Web $3.0^{5}$. A rede está pronta para ser explorada, mas seus exploradores ainda encontram-se sem os mapas para realizar essa exploração.

Alguns fatores, como os colocados no tripé Educação-Renda-TIC, ainda são impeditivos para muitos brasileiros, o que só faz aumentar a brecha digital, também chamada de divisão digital, infoexclusão, ou ainda exclusão digital. 0 fato é que boa parte da população brasileira está muito distante da tecnologia. Vários fatores podem explicar essa distância, seja pela disparidade social, seja pelo nosso atraso tecnológico, seja pela educação deficitária existente em nosso país. Esses fatores explicam, mas não modificam o cenário atual.

Medidas e políticas públicas devem ser gestadas com o propósito de abarcar o maior número de pessoas na rede. Mas sempre lembrando que não basta estar incluído na rede se essa inclusão não tiver significado, não produzir conhecimento (tácito e explícito) ou mudança para a vida do cidadão nela inserido. De acordo com Nazareno et al. (2006, p. 33)

De forma semelhante ao que se observa nas demais esferas socioeconômicas do País é possivel identificar a existência de um "apartheid digital" entre as regiões geográficas brasileiras, bem como entre os estratos sociais da população [...]. Exemplificando, enquanto que o Distrito Federal possui quase 40\% dos domicílios conectados à Internet, pouco mais de $11 \%$ de domicílios da região Norte dispõem do mesmo benefício.

É necessário que se compreenda que não basta apenas o avanço tecnológico, se ele não estiver atrelado a políticas públicas, educação, melhor distribuição de renda, habilidade tecnológica, metas e parcerias entre instituições públicas e privadas, para que se possa abarcar o maior número possível de cidadãos nesse universo digital, pois a tecnologia, por si, é incapaz de prover qualquer mudança.

Nesse cenário incerto e turvo, o termo cidadania digital está intimamente relacionado à ampliação dos direitos já conquistados nos campos social, político, econômico e cultural também para as redes digitais, principalmente para aquelas que utilizam as tecnologias da informação e comunicação.

A cidadania, conforme aponta Carvalho (2004, p. 9), abarca muitas dimensões. "Algumas podem estar presentes sem as outras. Uma cidadania plena, que combine liberdade, participação e igualdade para todos, é um ideal [...] talvez inatingível". Podemos considerar que a cidadania seja a junção dos direitos civis, políticos e sociais. "0 cidadão pleno seria aquele que fosse titular dos três direitos [...]" (CARVALHO, 2004, p. 9).

Quando o cidadão passa a ser privado do acesso a determinado instrumental, também passa a ser privado do seu direito. 0 Estado, em sua soberania, deve garantir meios para que esse acesso seja possível. Muitos podem dizer que o governo deve priorizar outros

5 "Todavia, enquanto ainda se discute sobre o que faz a Web 2.0, novos conceitos, tecnologias e serviços já começam a despontar em direção a uma possivel Web 3.0 ou Web Semântica. Esta seria uma espécie de ambiente no qual as máquinas conseguem ler as informações, agregando um significado, um entendimento a elas" (PATRIOTA; PIMENTA, 2008, p. 2). 
direitos mais "urgentes" como a educação, saúde e moradia. Mas é fundamental que se compreenda que a cidadania digital é uma ampliação aos direitos já postos e não pode ser deixada para trás. Como o próprio Bell (1973, p. 32) nota, a sociedade pós-industrial "organiza-se em torno do conhecimento, a fim de exercer o controle social e a direção das inovações e mudanças; e isto tudo dá origem, por sua vez, a novos relacionamentos sociais e a novas estruturas, as quais têm de ser politicamente dirigidas".

Os projetos de inclusão digital concebidos no início da sociedade da informação no Brasil buscavam apenas a inserção do cidadão na rede, ou seja, privilegiavam apenas o acesso. Naquele momento, a apresentação à tecnologia talvez fosse uma boa alternativa, já que pouco se sabia sobre seu potencial. Com medidas tecnicistas, e que pouco valorizam a produção de informação e conhecimento, o governo brasileiro, a partir de 2003 mais significativamente, vem criando ações para a inclusão digital (MCT, 2006). A sociedade civil também tem se organizado desde a implantação da internet no País com projetos que valorizam a conectividade. Dessa maneira, os projetos de inclusão digital apresentados na fase da conectividade e o potencial cognitivo e inteligente dos cidadãos conectados não se apresentam valorizados. Nesse sentido, a criação de coletivos inteligentes é mais que uma necessidade para os países periféricos.

Com a introdução das tecnologias, acredita-se em um novo "paradigma tecnoeconômico", um "fenômeno global" capaz de transformar as atividades sociais e econômicas. Da mesma forma, a ausência de conhecimento sobre essas tecnologias, por parte das nações, pode gerar um atraso mundial da sociedade global.

0 uso da informação deve estar atrelado à melhoria da qualidade educacional e ao incremento da alfabetização da população. Mas o que se observa atualmente é que a simples conectividade, ou simples acesso às TIC, não garante ao cidadão o uso da informação, como se ela por si pudesse fazer com o que o indivíduo conectado possa encontrar os caminhos, processar, disseminar e transformar a informação recebida e a ser transmitida.

Devemos ressaltar que a partir de 2003, com a mudança de governo, com o presidente Luis Inácio Lula da Silva, mesmo por que o governo anterior pouco conseguiu fazer para colocar a sociedade da informação em pé, passou-se a privilegiar os programas de inclusão digital que pudessem inserir os cidadãos de baixa renda nas TIC.

0 Programa Brasileiro de Inclusão Digital do Governo Federal, iniciado em 2003, atualmente é composto pelos seguintes programas e projetos: Centros de Inclusão Digital, Computador para Todos; CVT - Centros Vocacionais Tecnológicos; Gesac - Governo Eletrônico Serviço de Atendimento ao Cidadão; Kits Telecentros; Maré - Telecentros da Pesca; Observatório Nacional de Inclusão Digital; Pontos de Cultura - Cultura Digital, Programa Banda Larga nas Escolas; Programa Computador Portátil para Professores; Programa Estação Digital; Programa SERPRO de Inclusão Digital - PSID; Prolnfo Programa Nacional de Informática na Educação; Projeto Computadores para Inclusão; Quiosque do Cidadão; Telecentros Banco do Brasil; Territórios Digitais; TIN - Telecentros 
de Informação e Negócios; UCA - Projeto Um Computador Por Aluno; e Casa Brasil.

Os Centros de Inclusão Digital é um projeto de ação do Ministério da Ciência e Tecnologia (MCT), de responsabilidade da Secretaria de Ciência e Tecnologia para Inclusão Social (SECIS), que tem como objetivo a implantação de Centros de Inclusão Digital, tendo como público-alvo a população menos favorecida e visa ao acesso às TIC por meio da capacitação e da prática das técnicas computacionais. Tem como foco o aperfeiçoamento da qualidade profissional e a melhoria do ensino.

O Computador para Todos é uma ação da Presidência da República, Ministério do Desenvolvimento, Ministério da Ciência e Tecnologia e Serpro, especificamente destinado à classe $C$, focado na oferta de computador e acesso à Internet a preços subsidiados, tendo linhas de financiamentos específicas e de isenção de impostos PIS/COFINS.

A posição do governo brasileiro em relação ao uso das TIC e da apropriação do espaço público virtual mostra que a inclusão digital, apesar de ser importante, é insuficiente, já que a prática discursiva tem sido diferente da prática não-discursiva. Para o Programa Sociedade da Informação no Brasil

tem sido importante a criação de conteúdos que facilitem a vida do cidadão [...] Há um vasto conjunto de informações relacionadas ao cotidiano das pessoas cuja disponibilidade seria um grande facilitador na interação entre o cidadão e o Estado. (TAKAHASHI, 2000, p. 33).

0 alargamento da brecha digital é evidente e as ações propostas até o momento não dão conta do contingente de excluídos do país, já que as desigualdades sociais no Brasil, como a falta de trabalho e de terra, fome, educação, moradia, saneamento básico, saúde e tantas outras que, direta ou indiretamente, afetam o dia-a-dia do cidadão e, consequentemente, seus direitos como tal, não são recentes nem tampouco imperceptíveis. "Na verdade, a única inclusão ou exclusão que existe é a social - de conhecimento, informação, gênero, raça, justiça e cidadania" (RANGEL, 2003).

0 Observatório Nacional de Inclusão Digital (ONID) ${ }^{6}$ que foi uma ação do Ministério do Planejamento, Orçamento e Gestão e parceiros para o agrupamento de informações sobre todos os programas de inclusão digital do Governo Federal, desde a mudança de gestão do Governo de Luis Inácio Lula da Silva para Dilma Rousseff está inativo, mesmo sendo citado no Portal do Governo ${ }^{7}$. Hoje todas as ações de inclusão digital estão dispersas, podendo ser encontradas em partes nos Ministérios de Ciência e Tecnologia ${ }^{8}$ e Comunicação $0^{9}$. Isso mostra a desarticulação do governo em relação as ações voltadas à inclusão digital e, consequentemente, que possam ampliar a cidadania digital.

6 Disponível em: http://www.onid.org.br/portal/ . Acesso em janeiro de 2010

7 Disponivel em: http://www.governoeletronico.gov.br/acoes-e-projetos/onid

8 Disponivel em:http://www.mct.gov.br/index.php/content/view/77601.html

9 Disponivel em: http://www.mc.gov.br/inclusao-digital/acoes-e-programas 


\section{A (des)articulação das políticas Públicas de Inclusão e Cidadania Digital no Brasil}

Na sociedade da informação, o uso da informação é a peça-chave para que um cidadão possa se tornar um agente ativo dentro da rede. Ao absorver e produzir novos conteúdos, ele gera coletivos inteligentes que podem alimentar o ciclo informacional: informação - conhecimento - desenvolvimento - informação (BARRETO, 1998). Segundo a UNESCO (1987), "informação é um produto social e não comercial [...] Informação é, ao mesmo tempo, uma necessidade social e um elemento essencial no pleno exercício dos direitos humanos". Evidentemente, partindo dos princípios colocados pelo Direito à Informação. Quando tratamos dos meios que sobrevivem da informação como produto comercial, em especial a mídia impressa e audiovisual, essa lógica é invertida.

0 Estado, como o guardião dos direitos e deveres do cidadão, deve criar mecanismos para que o uso da informação seja garantido a todo indivíduo, já que "a informação no contexto do Estado está voltada para a análise da realidade social, e subsequente elaboração, aplicação e controle de políticas públicas [...] o Estado precisa encarar a informação como um recurso de gestão e desenvolvimento para o país" (FERREIRA, 2003, p. 37).

Em contrapartida, a sociedade civil tem por obrigação desenvolver o potencial criativo e intelectual dos indivíduos, dando sentido às ações realizadas pelo cidadão em seu cotidiano. Isso gera mecanismos para que os seus anseios possam ser tornados públicos por meio de políticas governamentais, refletindo assim diretamente na qualidade de vida da população e permitindo "o exercício da cidadania, o que só é possível se os cidadãos tiverem o pleno conhecimento de seus direitos e deveres" (FERREIRA, 2003, p. 37).

Assim "a rede pode exercer um enorme contrapoder, seja no sentido político ou econômico. Explorando a multidirecionalidade das redes, o seu potencial interativo, a prática comunicativa por meio da internet é transnacional, ou seja, ultrapassa as fronteiras nacionais" (SILVEIRA, 2008, p. 34). E, porque não, dizer que a rede pode criar um empoderamento por parte do cidadão. Mas, de pouco adianta dar noção de informática se, ao ser inserido na rede, o indivíduo só consegue utilizar o correio eletrônico ou redes sociais, estando assim subutilizada a sua capacidade de produzir, transformar e receber outras informações que sejam úteis ao seu dia-a-dia e ao seu posicionamento enquanto cidadão. A exclusão digital ocorre ao se privar o indivíduo do uso da tecnologia, da informação, do conhecimento e de todo o potencial que a rede oferece. Portanto, não basta estar conectado se não conhecer a potencialidade do sistema para utilizá-lo estrategicamente. As redes sociais são importantes, tanto quanto os correios eletrônicos, mas há necessidade de se filtrar, se selecionar as informações, eles podem ser um meio, mas não um fim para toda a atividade possível dentro da rede.

Atualmente a inserção na chamada sociedade da informação para os brasileiros excluídos têm se dado apenas pelo acesso e não pela estimulação da inteligência coletiva. Podemos dizer que ainda estamos na pré-história da inclusão digital. Portanto, a 
iniciativa deve ser bem articulada política e socialmente, por meio de políticas públicas e de ações governamentais e, também, que envolvam as instituições do Terceiro Setor e da iniciativa privada. 0 uso da informação deve ser o ponto central para que qualquer projeto ou programa de inclusão digital possa realmente ter impacto na vida de uma pessoa. De acordo com Rocha (2000, p. 41), a informação contribui de dois modos para o crescimento e para o desenvolvimento: "primeiro, porque a produção e distribuição de informação é uma atividade econômica; segundo, porque a aplicação do conhecimento melhora a produtividade e a qualidade de outros bens e serviços".

A desarticulação das políticas públicas de inclusão e cidadania digital demonstra que estamos num solo árido. 0 governo federal tem se utilizado do discurso que o Programa Nacional de Banda Larga (PNBL) ${ }^{10}$ resolverá a questão da inclusão digital. Mas o cenário é bem mais complexo. Com uma estrutura defasada (1 mega), um serviço oferecido a um preço inacessível à muitos brasileiros ( $\mathrm{R} \$ 35,00$, cerca de 15 dólares) e a dificuldade de implementação em áreas que normalmente não são beneficiadas pelas políticas públicas nacionais, a semântica governamental não convence.

De acordo com o balanço do $\mathrm{PNBL}^{11}$ em março de 2013, 2.930 cidades atendidas, com 68,2 milhões de acessos, com previsão que até 2015 a área correspondente a um raio de $30 \mathrm{~km}$ a partir da localidade sede de todos os municípios brasileiros seja coberta por serviços de voz e dados, o que alcançará $91 \%$ da população rural. 0 que o governo desconsidera nas análises, gráficos e notícias acerca do PNBL, é que em muitas das regiões contempladas, a tecnologia já chega atrasada e defasada, uma vez que o fluxo e volume de informações são cada vez maiores.

Centrar todas as metas previstas no Livro Verde para a Sociedade da Informação em mostra o despreparo governamental em entender a importância de uma sociedade da informação equânime, acessivel e possivel.

\section{Considerações Finais}

A superação do abismo social que aparta e estratifica nossa sociedade solidifica a ideia que a inclusão social, em sua dimensão digital, é uma questão de direito à cidadania. Incluir digitalmente é criar uma rede digital que possa "[...] garantir que manifestações culturais brasileiras transitem por ela e cidadãos acessem gratuitamente aplicações, serviços públicos, informação e entretenimento." (BRASIL, 2010, p.59). Ao não participar dessa sociedade marcada pela inteligência coletiva, o cidadão passa a ficar à margem, o que gera atraso nas estruturas econômica, política, cultural e social. 0 acesso ao mundo conectado da internet deve ser entendido "como um instrumento de efetivação de direitos dos cidadãos da era digital" (idem, 2010, p.07).

10 Disponivel em: http://www.mc.gov.br/acoes-e-programas/programa-nacional-de-banda-larga-pnbl

11 Disponivel em: http://www.mc.gov.br/editais-e-avisos/doc_download/1419-balanco-2010-2013 
A rapidez com que se processam os avanços tecnológicos é outro impeditivo para que a população de países em desenvolvimento consigam fazer parte da sociedade da informação. Muitas vezes com um nível educacional baixo, com falta de recursos econômicos e com falta de habilidade para seu manuseio, o cidadão não só fica fora das redes digitais como também de todo o universo que elas englobam.

Embora o desenvolvimento do Brasil dependa da implantação de políticas de incentivo aos setores produtivos e tecnológicos, a questão social da inclusão digital não pode estar à margem ou desarticulada em relação às demais políticas de inclusão e direito à cidadania e tampouco atrelada apenas a interesses mercadológicos. Enfim, a inclusão digital gera efeitos valorosos que promovem a cidadania, evita a concentração de oportunidades em determinadas regiões e estratos sociais e promove a democratização do acesso informação.

Enfim, fatores como o tripé Educação-Renda-TIC aumentam a brecha digital e os projetos de inclusão digital como os concebidos no início da sociedade da informação no Brasil como o Programa Brasileiro de Inclusão Digital do Governo Federal, iniciado em 2003, buscam apenas a inserção do cidadão na rede, ou seja, privilegiavam apenas o acesso por meio de uma política que mais atende aos interesses das concessionárias de telefonia móvel do que as necessidades dos cidadãos brasileiros. 0 alargamento da brecha digital é evidente e as ações propostas até o momento estão desarticuladas e não dão conta do contingente de excluídos do país. 0 que se propaga, erroneamente nestes projetos, é que a simples conectividade, ou acesso às TIC, garante ao cidadão o uso da informação, como se ela por si pudesse fazer com o que o indivíduo conectado possa encontrar os caminhos, processar, disseminar e transformar a informação recebida e a ser transmitida.

\section{Referências}

BARRETO, A. (1998). Mudança estrutural no fluxo do conhecimento: a comunicação eletrônica. Ciência da Informação, Brasília, v. 27, n. 2, p. 122-127, maio/ago.

BELL, D. (1973) . 0 advento da sociedade pós-industrial: uma tentativa de previsão social. São Paulo: Cultrix.

. (1980). The social framework of the information society. S.n.d.

BRASIL. (2010). Comitê Gestor do Programa de Inclusão Digital [CGPID]. Secretaria-Executiva. Programa Nacional de Banda Larga. Brasilia. Disponível em: <http://www4.planalto. gov.br/brasilconectado/forum-brasil-conectado/documentos/3o-fbc/documento-basedo-programa-nacional-de-banda-larga>. (Última consulta: 13 jun. 2011).

BRZEZINSKI, Z. (1971). Between two ages: America's role in the technetronic era. Nova York: Viking Press.

CARVALHO, J. M. de. (2004) Cidadania no Brasil: o longo caminho. Rio de Janeiro: Civi- 
lização Brasileira.

FELICIANO, A. M. (2008) Contribuições da gestão do conhecimento para ações empreendedoras de inclusão digital. 2008. 224 f. Dissertação (Mestrado em Engenharia e Gestão do Conhecimento) - Universidade Federal de Santa Catarina, Florianópolis, 2008.

FERREIRA, R. da S. S. (2003) A sociedade da informação no Brasil: um ensaio sobre os desafios do estado. Ciência da Informação, Brasília, v. 32, n. 1, p. 36-41, jan./abr.

FREITAS, L. S. (2002). A memória polêmica da noção de sociedade da informação e sua relação com a área de informação. Informação \& sociedade, João Pessoa, v. 12, n. 2. GOLDHABER. M. H. (1997) The attention economy and the net. First Monday, Bridgman, v.2, n.4. Disponivel em: <http://firstmonday.org/htbin/cgiwrap/bin/ojs/index.php/fm/ article/view/519/440>. (Última consulta: 30 nov. 2010).

INSTITUTO NACIONAL DE METROLOGIA, NORMALIZAÇÃO E QUALIDADE INDUSTRIAL [INMETRO].(2011) Relatório sobre análise em provedores de banda larga. Rio de Janeiro. Disponivel em: <http://www.inmetro.gov.br/consumidor/produtos/banda-larga.pdf>. (Última consulta: 20 jun. 2011).

INSTITUTO DE PESQUISA ECONÔMICA APLICADA [IPEA]. (2010) Análise e recomendações para as políticas públicas de massificação de acesso à internet em banda larga. Brasília. (Comunicado IPEA, n.46). Disponível em: <http://www.ipea.gov.br/portal/images/ stories/PDFs/100426_comunicadodoipea_n_46.pdf>. (Última consulta: 20 jun. 2011).

KURMAR, K. (1997). Da sociedade pós-industrial à pós-moderna: novas teorias sobre 0 mundo contemporâneo. Rio de Janeiro: Jorge Zahar Editor.

LEINER, M. B. et al. (2011) Brief History of the Internet. Disponivel em: <http://www.isoc. org/internet/history/brief.shtml>. (Última consulta: 23 jun. 2011).

LÉVY, Pierre. (2001) A conexão planetária: o mercado, o ciberespaço, a consciência. Tradução de Maria Lúcia Homem e Ronaldo Entler. São Paulo: editora 34.

MAGNONI, A. F.; AFINNI, L. P.; AMÉRICO, M. (2007) Da mobilidade a ubiqüidade da comunicação. In: CONGRESSO BRASILEIRO DE CIÊNCIAS DA COMUNICAÇÃO, 30., 2007, Santos. Anais... Santos: Intercom. Mesa apresentada no Multicom - II Colóquios Multitemáticos em Comunicação. Disponível em: <http://www.intercom.org.br/papers/ nacionais/2007/resumos/R0811-2.pdf>. (Última consulta: 13 jun. 2011).

MASUDA, Y.(1968). Introdução à sociedade da informação. Tokyo: Perikan-Sha.

MATTELART, A. (2002). História da sociedade da informação. São Paulo: Loyola, 2002.

MCLUHAN, Marshall. (1977) Os meios de comunicação como extensões do homem. Tradução de Décio Pignatari. 4. ed. São Paulo: Cultrix.

MINISTÉRIO DA CIÊNCIA E TECNOLOGIA. (2006) Inclusão digital. Brasilia: MCT. Disponível em: <http://www.mct.gov.br>. (Última consulta: 17 nov. 2008).

MINISTÉRIO DAS COMUNICAÇÕES. (2009) Base de dados. Brasília: Minicom. Disponível em: < http://www.mc.gov.br/>. (Última consulta: 05 jan. 2010).

NAZARENO, C. et al. (2006) Tecnologias da informação e sociedade: o panorama brasileiro. Brasilia: Câmara dos Deputados, Coordenação de Publicações. 187 p. (Série temas de 
interesse do legislativo; n. 9).

PATRIOTA, K. R. M. P.; PIMENTA, R. D. da H. (2008) Da mídia 2.0 para a mídia 3.0: perspectivas da próxima onda na web. IN: CONGRESSO BRASILEIRO DE CIÊNCIAS DA COMUNICAÇÃO, 31., 2008, Natal. Anais... Natal.

RACIONAIS MC'S. Negro Drama.(2002) In: RACIONAIS MC'S. Nada como um dia após o outro. Produção Racionais MC's e Zé Gonzales. São Paulo: Cosa Nostra. 1 CD. Faixa 6. RANGEL, A. M. (2003) Exclusão cefálica. Sete pontos. Rio de Janeiro, v. 1, n. 1, maio. Disponivel em <http://www.comunicacao.pro.br/setepontos/1/cefalica.htm>. (Última consulta: 8 fev. 2004).

ROCHA, M. P. C. A questão da cidadania na sociedade da informação. Ciência da Informação, Brasilia, v. 29, n. 1, p. 40-45, jan./abr. 2000.

SILVEIRA, S. (2001) Exclusão digital a miséria na era da informação. São Paulo: Fundação Perseu Abramo.

. Convergência digital, diversidade cultural e esfera pública. In: PRETTO, Nelson De Luca; SILVEIRA, Sérgio Amadeu (Orgs.). (2008) Além das redes de colaboração: internet, diversidade cultural e tecnologias do poder. Salvador: EDUFBA.

TAKAHASHI, T. (Org.). (2000) Sociedade da informação no Brasil: livro verde. Brasília: Ministério da Ciência e Tecnologia.

UNESCO. (1987) Communication and society: a documentary history of a new world information and communication order seen an evolving and continuous process, 1975-1986. Paris, UNESCO. 